\title{
RESISTÊNCIA AO CISALHAMENTO DE UM LATOSSOLO VERMELHO DISTROFÉRRICO SOB DIFERENTES SISTEMAS DE MANEJO
}

\author{
Carla Eloize Carducci ${ }^{1}$, Antonio Carlos Tadeu Vitorino², Anderson Cristian Bergamin ${ }^{3}$, \\ Walmes Marques Zeviani ${ }^{4}$
}

\begin{abstract}
RESUMO
A resistência do solo ao cisalhamento é um atributo que pode ser influenciado pela intensidade de uso e manejo do solo, resultando em significativas alterações nas propriedades físico-mecânicas do mesmo. Este trabalho teve como objetivo avaliar a resistência ao cisalhamento de um Latossolo Vermelho Distroférrico submetido a diferentes sistemas de uso e manejo, por meio de ensaio de palhetas com 'Vane Shear Test' em laboratório. O estudo foi realizado em amostras com estrutura preservada, coletadas em áreas sob sistema plantio direto, pastagem e mata nativa, no município de Dourados-MS. O delineamento foi inteiramente casualizado em sistema fatorial (3 manejos x 2 profundidades x 7 repetições), em cada uso foram tomadas amostras nas profundidades 0-0,05 e 0,05-0,10 m, as quais foram equilibradas ao potencial matricial de $6 \mathrm{kPa}$ em câmara de pressão de Richards. Em seguida foram submetidas ao ensaio de palhetas para a determinação do valor de resistência ao cisalhamento e densidade do solo. Os maiores valores para resistência ao cisalhamento e densidade do solo foram encontrados na área sob pastagem. A resistência do solo ao cisalhamento esteve associada ao aumento da densidade do solo, uso e manejo, de forma distinta entre as profundidades estudadas.
\end{abstract}

Palavras-chave: resistência mecânica, densidade do solo, manejo do solo

\section{ABSTRACT \\ SHEAR STRENGTH OF A DYSTROPHIC RED LATOSOL UNDER DIFFERENT MANAGEMENT SYSTEMS DETERMINED BY VANE TEST}

The soil shear strength can be influenced by the use intensity and management of soil, resulting in considerable changes in its physical-mechanical properties. This study evaluated the shear strength of a Red Oxisol dystrophic soil subjected to different uses and management systems, using Vane Shear Test in the laboratory. Samples with preserved structure were collected from areas under no-tillage, pasture or native forest in the city of Dourados-MS. The samples were collected to depths of 0 to 0.05 and from 0.05 to $0.10 \mathrm{~m}$, in seven replications. After equilibrating to matric potential of $6 \mathrm{kPa}$ in the Richards' pressure chamber, each sample was subjected to the vane to determine shear strength and bulk density. The maximum shear strength and bulk density was found in the area under pasture. The shear strength was associated with increased density, use and management, but distinctly at two depths.

Keywords: mechanical strength, bulk density, soil management

\section{Recebido para publicação em 31/05/2010. Aprovado em 20/10/2011.}

1- Engenheira Agrônoma, Doutoranda do Curso de Pós-graduação em Ciência do Solo, Bolsista CNPq, Universidade Federal de Lavras, UFLA/Lavras-MG, elocarducci@hotmail.com;

2- Engenheiro Agrônomo, Professor Adjunto IV da UFGD/Dourados, MS, Bolsista CNPq, vitorino@ufgd.edu.br;

3- Engenheiro Agrônomo, Professor Assistente I da IEAA/UFAM/Humaitá-AM, andersonbergamin@hotmail.com;

4- Engenheiro Agrônomo, Professor Assistente I da UFPR/Curitiba-PR, walmes@ufpr.br. 


\section{INTRODUÇÃO}

A intensificação do uso do solo associada ao emprego de máquinas agrícolas cada vez mais pesadas altera significativamente suas propriedades físico-mecânicas (STRECK et al., 2004; SILVA et al., 2004). As diversas operações mecanizadas, realizadas muitas vezes de maneira inadequada, podem provocar um impacto no ambiente com conseqüências negativas para a qualidade do solo, da água e da biodiversidade, além da redução da produção agrícola. A elaboração de estratégias de manejo que maximizem a produção das culturas e minimizem a degradação ambiental se torna uma ferramenta necessária para a tomada de decisão na escolha do manejo mais adequado e das operações mecanizadas.

Os implementos utilizados nos diversos sistemas de manejo do solo promovem alterações nas propriedades físico-mecânicas, químicas e biológicas do solo, uma vez que, cada implemento trabalha o solo de maneira própria, alterando, de maneira diferenciada estas propriedades (SÁ, 1998). Exemplos desse efeito são considerados em estudos apresentados na avaliação da compactação e suas relações com o aumento da densidade (IMHOFF et al., 2000) e da resistência mecânica do solo à penetração (CONTE et al., 2007; STRECK et al., 2004).

No sistema plantio direto, o revolvimento do solo apenas na linha de semeadura permite que, após alguns anos de cultivo, o solo adquira estrutura mais densa e resistente (BRAIDA, 2004; BRAIDA et al., 2008), bem como, o tráfego sistemático de máquinas promove excessiva compactação na superfície do solo, aumentando a densidade e sua resistência mecânica (SECCO et al., 2004; SERAFIM et al., 2008).

Além da ação das máquinas e equipamentos que promovem a compactação, percebe-se também que a estrutura do solo pode ser alterada quando o mesmo é usado em atividade pecuária, onde o pisoteio animal pode influenciar no processo compressivo do solo. Em área sob pastejo Imhoff et al. (2000), verificaram que a diminuição do conteúdo de água em conjunto com a elevação da densidade do solo, provocado pelo pisoteio de animais, promoveu aumento acentuado na resistência do solo à penetração.

Assim sendo, o solo frequentemente sofre deformações em função da intensidade e frequência de aplicação de cargas sobre ele. A intensidade deste fenômeno gera mudanças nas características do mesmo, assim como no comportamento tensãodeformação (FURLAN, 2000). No entanto muitos autores (TERZAGHI \& PECK, 1962; CAPUTO, 1980; VARGAS, 1977; BALASTREIRE, 1990), afirmam que quando a tensão cisalhante em uma massa de solo excede um valor crítico, o solo se rompe, portanto, a resistência ao cisalhamento é definida como a tensão máxima cisalhante que o solo pode suportar sem sofrer ruptura (PINTO, 2000; CAVALCANTE, 2006).

A resistência do solo ao cisalhamento é influenciada pela forma e distribuição de partículas do solo, estrutura, densidade, conteúdo de água (MCCORMACK \& WILDING, 1979; SILVA \& CARVALHO, 2007), tipo de argilomineral, óxidos de ferro e de alumínio (SILVA \& CABEDA, 2005) tipo e quantidade de cátions presentes e forças de repulsão e atração entre as partículas. Portanto, a resistência do solo ao cisalhamento é uma propriedade indicativa da qualidade estrutural do solo e de seu estado de compactação (NUNES, 2010).

A resistência ao cisalhamento é usualmente determinada em laboratório e a adoção de um método de ensaio para a sua determinação requer a análise das propriedades do solo para se obter maior precisão dos resultados(FURLAN, 2000; CAPUTO, 1980). Dentre os diversos ensaios de determinação à resistência ao cisalhamento pode-se citar: o ensaio de palhetas em laboratório (BAUER et al., 2004; FURLAN, 2000), ensaio de palhetas in situ (CARDIM, 2008), cisalhamento direto (NUNES, 2010), compressão simples não confinada e compressão triaxial confinada (TRINDADE et al., 2006).

O ensaio de palheta ou Vane Shear Test é preconizado pela norma ASTM D4648-2000, destacando-se pela sua simplicidade, facilidade de limpeza, rápida determinação da tensão cisalhante como vantagens e a eliminação de erros graves ou robustes, como a possibilidade de deslizamento da amostra, aparelhagem durável de baixo custo e fácil emprego nos serviços de qualquer laboratório, produzindo resultados rápidos e confiáveis (BAUER et al., 2004; BAUER et al., 2005 ).

\section{REVENG} 423-431 p.

ENGENHARIA NA AGRICULTURA, VIÇOSA - MG, V.20 N.5, SETEMBRO / OUTUBRO 2012 
A partir do exposto acima, este trabalho teve como objetivo avaliar a resistência ao cisalhamento de um Latossolo Vermelho Distroférrico, sob diferentes sistemas de uso e manejo, por meio do ensaio de palhetas com Vane Shear Test em laboratório.

\section{MATERIAL E MÉTODOS}

O experimento foi realizado no ano agrícola de 2007/2008. As amostras de solo foram coletadas na área experimental da faculdade UNIDERP/ ANHANGUERA, situada no município de Dourados-MS. O clima da região é classificado como do tipo Cwa, segundo a classificação de Köppen. De acordo com a Embrapa (2006), o solo em estudo foi classificado como Latossolo Vermelho distroférrico (LVdf) de textura muito argilosa. Foram avaliadas três áreas com diferentes sistemas de manejo do solo, a saber: 1- área sob sistema de plantio direto (PD) que vinha sendo cultivada com soja; 2- área sob pastagem (P) cultivada com Brachiaria brizanta e pastejada (ambos há dez anos); 3- área sob mata nativa (MN) (Tabela 1).

Em cada sistema de manejo foram abertas sete trincheiras aleatoriamente e coletadas amostras com estrutura preservada utilizando anéis volumétricos de $58,9 \mathrm{~cm}^{3} \mathrm{com}$ auxílio do amostrador do tipo Uhland nas profundidades de 0-0,05 e 0,05-0,10 $\mathrm{m}$, sendo estas as profundidade que estão sob efeito direto dos sistemas avaliados, como também amostras deformadas para a análise granulométrica pelo método da pipeta, onde foi obtida por meio de agitação rápida (10.000 rpm) para a dispersão física e NaOH $1 \mathrm{~mol}_{c} \mathrm{~L}^{-1} \mathrm{em}$ contato com a amostra durante 24 horas para dispersão química (EMBRAPA, 1997) (Quadro 1).

Posteriormente, as amostras com estrutura preservada foram saturadas por meio da elevação gradual de uma lâmina de água até atingir cerca de dois terços da altura do anel, em uma bandeja com areia fina lavada, coberta com papel mataborrão por 24 horas (SERAFIM et al., 2008). Seguidamente foram submetidas ao potencial matricial $\left(\Psi_{m}\right)$ de $6 \mathrm{kPa}$ na câmara extratora de Richards de placas porosas (EMBRAPA, 1997) até sua estabilização. A padronização do potencial matricial, se refere ao ponto de inflexão para os Latossolos, ou seja o limite entre macroporos e microporos (MELLO et al., 2002; OLIVEIRA et al., 2004), onde o conteúdo de água é facilmente disponível às plantas (DEXTER \& BIRD, 2001).

O ensaio de palhetas foi executado de acordo com a norma ASTM D 4648:2000 que descreve o procedimento deste ensaio, como: inserção de uma palheta com duas lâminas montadas em forma de cruz na amostra e girar a palheta lentamente através de um dispositivo de rotação $(60$ a $90 \% \mathrm{~min})$ até o cisalhamento da amostra (torque máximo). A forma de cisalhamento em volta das palhetas é cilíndrica, não ocorrendo cisalhamento no interior do círculo circunscrito pelas lâminas (BAUER et al., 2005).

$\mathrm{O}$ torque pode ser definido como a soma das contribuições do cisalhamento exercido pela superfície lateral e das duas superfícies, superior e inferior, da palheta (BAUER et al., 2005); ou seja, o torque é o movimento necessário para provocar a ruptura do solo, caracterizado pela velocidade angular da palheta, que em outras palavras, é quando esta gira de forma livre com um grau de rotação previamente calibrado (FURLAN, 2000).

$\mathrm{Na}$ abordagem convencional da mecânica dos solos assume-se que o cisalhamento do material dá-se ao longo de uma superfície cilíndrica de área $\pi D H+2\left(\pi D^{2} / 4\right)$, onde $D$ e $H$ são o diâmetro e altura da palheta respectivamente. A tensão cisalhante é uniformemente distribuída ao longo do cilindro, onde o torque é máximo (BAUER et al., 2005).

Quadro1. Valores médios de argila, silte, areia de um Latossolo Vermelho Distroférrico nas profundidades de 0-0,05 e 0,05-0,10 $\mathrm{m}$ sob diferentes manejos

\begin{tabular}{|c|c|c|c|c|c|c|c|c|c|}
\hline \multirow{2}{*}{ Profundidade (m) } & \multicolumn{3}{|c|}{ Plantio Direto } & \multicolumn{3}{|c|}{ Pastagem } & \multicolumn{3}{|c|}{ Mata nativa } \\
\hline & Argila & Silte & Areia & Argila & Silte & Areia & Argila & Silte & Areia \\
\hline & & & & ..........g. & $\mathrm{g}^{-1} \ldots \ldots$ & & & & \\
\hline $0-0,05$ & 684,0 & 182,1 & 133,9 & 669,2 & 218,2 & 112,6 & 683,4 & 218,6 & 98,0 \\
\hline $0,05-0,10$ & 663,0 & 200,2 & 136,8 & 672,5 & 213,2 & 114,3 & 711,2 & 198,4 & 90,4 \\
\hline
\end{tabular}


Ao dimensionar a palheta deve-se respeitar no mínimo 20 vezes a dimensão máxima característica do material em estudo, com o intuito de minimizar perturbações no material durante a penetração da palheta na amostra, devido possível deformação da amostra no momento da inserção da palheta que pode alterar as características do cisalhamento (FURLAN, 2000) e definição da superfície cisalhada. Podem-se utilizar palhetas com a relação entre altura/diâmetro $H / D=2$ ou relação $H / D=1$ (BAUER et al., 2004; BAUER et al., 2006). Segundo Barnes e Nguyen (2001), a haste deve ter o tamanho mínimo igual a duas vezes a altura da palheta assegurando dessa forma que o topo da palheta esteja inserido numa profundidade mínima de uma altura da palheta abaixo da superfície da amostra. $\mathrm{O}$ anel, ou porta amostra, deve ter um diâmetro mínimo de dois diâmetros da palheta.

Para a determinação da tensão de cisalhamento foi empregado o aparelho Vane Shear Test da marca V-Lab, fabricado pela Via Test. Este é equipado com duas lâminas em forma de cruz formando uma palheta com dimensões de $13 \times 13 \mathrm{~mm}$, correspondendo a descrição de Bauer et al. (2004), altura dividida pelo diâmetro da palheta foi igual a um $(\mathrm{H} / \mathrm{D}=1)$. Com o auxilio do gráfico de calibração do mesmo, disponível no manual do fabricante, pode se observar a relação do grau de deflexão e do torque (N.m) a ser empregado no ensaio. A definição da melhor tensão é obtida após sucessivos testes com as molas tensoras e com o solo em estudo, no caso deste trabalho a mola $n^{\circ} 4$ foi selecionada como a mais adequada na determinação do torque cisalhante (Figura 1).

O ensaio de palhetas iniciou-se após a estabilização da amostra ao $\Psi_{\mathrm{m}}$ de $6 \mathrm{kPa}$; prosseguiu-se com a inserção da palheta em forma de cruz na amostra de solo, utilizando a manivela situada na parte superior do equipamento, de forma a submergí-la por completo na amostra até alcançar a profundidade pré determinada, equivalente à altura da palheta. A velocidade utilizada foi de $60^{\circ} \mathrm{min}^{-1}$ de acordo com a norma ASTM D 4648:2000, obtida por meio do dispositivo manual (manivela) e pela escala de leituras de deformações localizada na parte superior do aparelho. Anotou-se o grau de deformação máxima medida. A situação de torque máximo ou ruptura fornece o valor da tensão limite de cisalhamento (BAUER et al., 2005). Em seguida, as amostras contidas nos anéis foram secas em estufa a $105-110{ }^{\circ} \mathrm{C}$ para determinação da densidade do solo segundo Embrapa (1997).

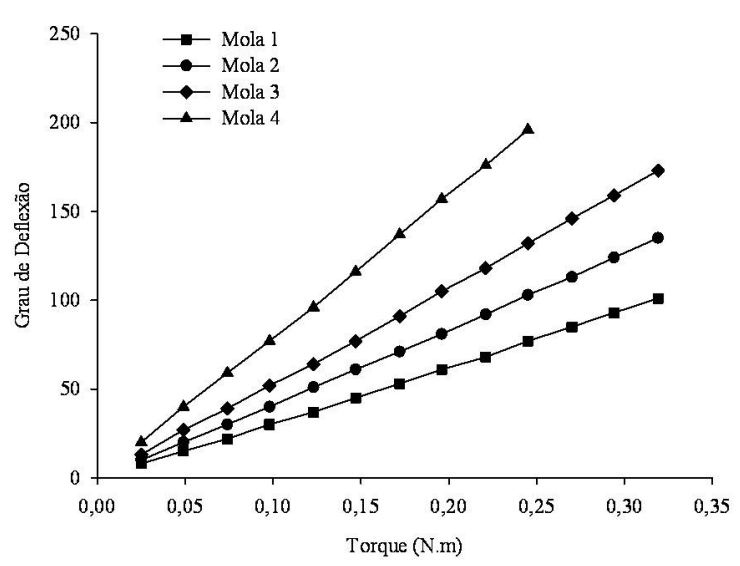

Figura 1. Gráfico de calibração das molas tensoras do aparelho Vane Shear Test.

Para fins do cálculo de resistência ao cisalhamento utilizou-se a Equação 1 dada por meio de gráfico de calibração do aparelho, obtendo-se o torque máximo, sendo este aplicado na Equação 2.

$\mathrm{T}_{\mathrm{Max}}=(\mathrm{GD}+0,398) / 798,5$

em que

GD = grau de deflexão medido;

$\mathrm{T}_{\mathrm{Max}}=$ torque máximo (N.m).

$\tau=T_{\text {Max }} \mathrm{x} k$

em que

$\tau=$ resistência ao cisalhamento $(\mathrm{kPa})$;

$T_{\text {Max }}=$ torque máximo (N.m);

$k=$ constante $1,33 \times 10^{5} \mathrm{~m}^{-3}$ (palhetas $12,7 \mathrm{a} 25,4 \mathrm{~mm}$ ).

Os resultados das análises dos atributos físicos e mecânicos do solo foram submetidos à análise de variância, segundo o delineamento inteiramente casualizado no sistema fatorial $3 \times 2 \times 7$ sendo três manejos, duas profundidades e sete repetições. As comparações das médias foram realizadas pelo teste de Tukey, a $5 \%$ de probabilidade, com auxilio do aplicativo computacional SAEG 9.2. Foram realizados testes de correlação de Pearson dos resultados. 


\section{RESULTADOS E DISCUSSÃO}

Os valores médios de resistência do solo ao cisalhamento e densidade do solo estão apresentados na Figura 2 e 3, respectivamente. Nas profundidades avaliadas, foram encontradas diferenças significativas $(p<0,05)$ entre os sistemas de manejo e profundidades, corroborando com os resultados obtidos por Silva e Cabeda (2005).

Na profundidade de 0-0,05 $\mathrm{m}$ foram observados os maiores valores de resistência ao cisalhamento para a área sob pastagem (P), sendo que, as áreas sob plantio direto $(\mathrm{PD})$ e mata nativa $(\mathrm{MN})$ não diferiram significativamente. A maior resistência ao cisalhamento na área sob $\mathrm{P}$ pode estar relacionada ao maior valor de densidade do solo (Figura 2 e 3), provavelmente ocasionada pela maior pressão de pastejo e pelas condições inadequadas de manejo da forrageira (IMHOFF et al., 2000; BERTOL et al., 1998) associado a maior carga animal influenciando portanto, no processo de compactação superficial do solo (CONTE et al., 2007) sendo a área em estudo submetida a dez anos sob pastejo.

Em áreas preservadas, como áreas de $\mathrm{MN}$, caso avaliado neste trabalho, o maior teor de matéria orgânica $\left(4,53 \mathrm{~g} \mathrm{dm}^{-3}\right)$ em conjunto com a não ação do homem sobre o solo (OLIVEIRA et al., 2004) podem conferir a este menor densidade, melhor agregação e porosidade (SILVA et al., 2000) influenciando sobremaneira na menor resistência do solo ao cisalhamento, entretanto, Silva et al. (2004) encontraram maiores valores de resistência em área de preservação, na região do Cerrado brasileiro.

O sistema plantio direto por ser considerado um sistema conservacionista, pois o revolvimento do solo ocorre somente na linha de semeadura (STRECK et al., 2004) e a presença de resíduos culturais, ou seja, material em decomposição na superfície (SILVA et al., 2000) influenciam beneficamente no aumento do volume de poros do solo, garantindo um bom desenvolvimento radicular, melhor infiltração e redistribuição de água no perfil do solo (KOAKOSKI et al., 2007). Neste trabalho as áreas apresentaram valores médios de $3,15 \mathrm{~g} \mathrm{dm}^{-3}$ de matéria orgânica, que posteriormente, resultarão em matéria orgânica do solo, o que pode conferir a menor resistência do solo ao cisalhamento dependendo da origem, tempo decorrido a incorporação da matéria orgânica, teor de água e textura do solo (BRAIDA et al., 2007).

As áreas sob PD e P, apresentaram os maiores valores de resistência do solo ao cisalhamento diferindo significativamente da área sob MN para a profundidade de 0,05-0,10 m (Figura 2). Em virtude de forças mecânicas oriundas do tráfego de máquinas e implementos agrícolas exercidas em sistema de plantio direto (OLIVEIRA et al., 2004) pode ocorrer alterações na estrutura do solo em camadas profundas, aproximando os agregados e aumentando sua resistência (SILVA et al., 2004; SPERA et al., 2009). Elevados valores de resistência mecânica e densidade do solo foram encontradas por Streck et al. (2004) até a profundidade de 0,28 m, ocasionada pela compactação imposta pelo tráfego de máquinas, fato este observado neste trabalho até a profundidade avaliada.

A compactação superficial em áreas de $\mathrm{P}$ está associada às altas pressões exercidas pelo pisoteio dos animais, que variam de acordo com seu peso (PROFFIT et al., 1993). Essas pressões podem ser transmitidas a camadas posteriores (BERTOL et al., 1998) podendo atingir até $0,10 \mathrm{~m}$ de profundidade, de acordo com Imhoff et al. (2000), que correlacionaram a alta resistência mecânica com valores de densidade do solo mais elevadas obtidas na profundidade de 0-0,10 m (Figura 3).

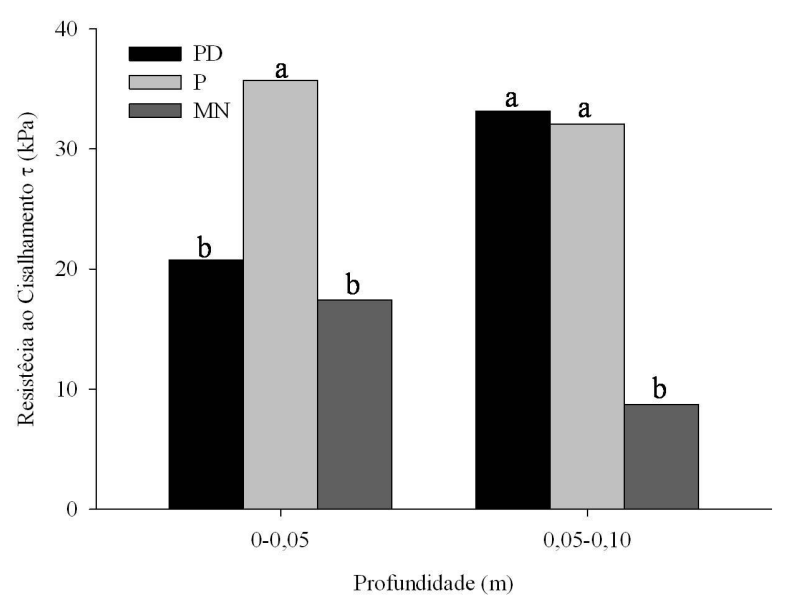

Figura 2. Valores médios de resistência ao cisalhamento de um Latossolo Vermelho Distroférrico (LVdf) nas profundidades de 0-0,05 e 0,05-0,10 $\mathrm{m}$ sob sistema plantio direto $(\mathrm{PD})$, pastagem $(\mathrm{P})$ e mata nativa $(\mathrm{MN})$. 
O sistema PD e P apresentaram maiores valores de densidade do solo na profundidade de 0-0,05 $\mathrm{m}$, diferindo significativamente da área sob $\mathrm{MN}$ (Figura 3). Apesar de ser um sistema que oferece um grande aporte de resíduo orgânico sobre a superfície do solo, tendo como uma de suas funções principais a de proteção do solo, acredita-se que após alguns anos de cultivo o sistema PD, desenvolve uma estrutura caracterizada por agregados mais densos e resistentes (BRAIDA, 2004) provocada pelo efeito cumulativo das atividades mecanizadas (SILVA \& CABEDA, 2005; SILVA et al., 2000) favorecidos pela aproximação de microagregados e, ou, partículas dispersas (SPERA et al., 2009), além da acomodação natural das partículas sólidas (STRECK et al., 2004).

A maior carga animal em menores alturas de forrageiras (CONTE et al., 2007) somados ao pisoteio destes em pastagens (IMHOFF et al., 2000) justifica os maiores valores de densidade do solo encontrados na área pastejada, diagnosticando primariamente o processo de compactação, pois o pastejo intenso provoca modificações nos atributos físicos do solo com magnitude suficiente para alterar sua condição estrutural (CONTE et al., 2007).

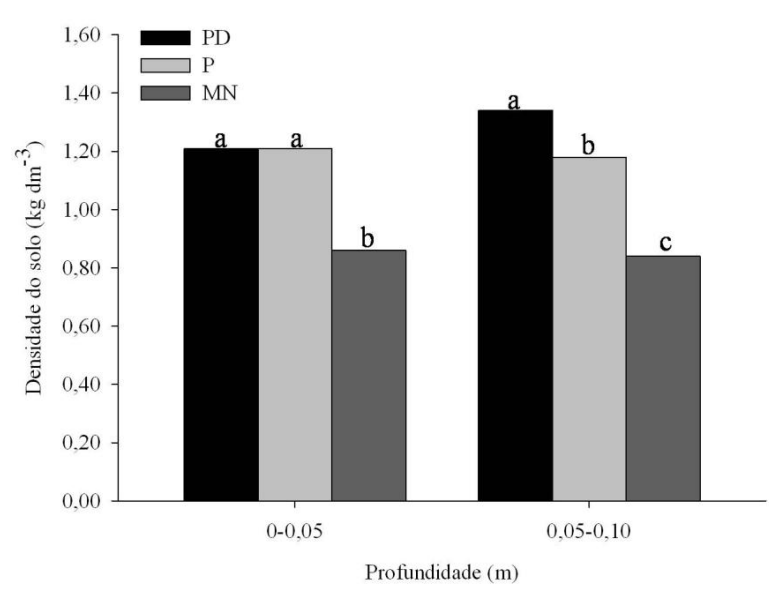

Figura 3. Valores médios de densidade um Latossolo Vermelho Distroférrico (LVdf) nas profundidades de 0-0,05 e $0,05-0,10 \mathrm{~m}$ sob sistema plantio direto $(\mathrm{PD})$, pastagem $(\mathrm{P})$ e mata nativa $(\mathrm{MN})$.

$\mathrm{Na}$ área sob $\mathrm{MN}$ os menores valores de resistência ao cisalhamento e densidade foram verificadas nas duas profundidades analisadas, possivelmente pelas características físicas do solo estarem preservadas devido a não ação antrópica (OLIVEIRA et al., 2004), com estrutura aberta e melhor porosidade (SILVA \& CABEDA, 2005), melhor estruturação ligada a maiores teores de matéria orgânica nas diferentes frações incorporados ao solo (LONGO, 1999). Solos compactados apresentam maior densidade e consequentemente elevada resistência ao cisalhamento, em razão da menor distância entre as partículas (SILVA \& CABEDA, 2005; NUNES, 2010).

Aplicando-se o teste de correlação de Pearson $(p>0,01)$ observou-se que existe uma correlação $(\mathrm{p}>0,05)$ direta com a densidade do solo ( $\mathrm{r}$ $=0,8127)$ e inversa $(r=-0,41)$ entre matéria orgânica e resistência ao cisalhamento, ou seja, os valores de resistência ao cisalhamento aumentam com a densidade do solo e diminuem à medida que os teores de matéria orgânica aumentam.

\section{CONCLUSÃO}

- O uso e manejo do solo influenciaram a resistência ao cisalhamento e na densidade do solo;

- Os maiores valores de resistência ao cisalhamento foram encontrados no sistema PD e P na profundidade de 0,05-0,10 m; e

- A área sob MN apresentou os menores valores de resistência ao cisalhamento e densidade para as duas profundidades avaliadas.

\section{AGRADECIMENTOS}

À Universidade Federal da Grande DouradosUFGD pelo apoio institucional e ao CNPq pelo apoio financeiro.

\section{REFERÊNCIAS BIBLIOGRÁFICAS}

AMERICAN SOCIETY FOR TESTING AND MATERIALS. ASTM D4648-00, Standard Test Method for Laboratory Miniature Vane Shear Test for Saturated Fine-Grained Clayey Soil Philadelphy, 2000. 
BALASTREIRE, L.A. Máquinas Agrícolas. São Paulo: Manoele, 1990.

BARNES, H.A.; NGUYEN, Q.D. Rotating vane rheometry - a review, Journal of non newtonian fluid mechanics. v. n.98, p.1-14, 2001.

BAUER, E.; MOTA, N.M.B.; KRAUS, E.; PEREIRA, C.H.A.F. Consistência das argamassas de revestimento e sua relação com a demanda de água e as partículas finas. Revista de Ciência e Tecnologia de Materiais de Construção Civil, v.3, n.2, p.91-102, 2006.

BAUER, E.; SANTOS, C.C.N.; MORAIS, D.M.; PEREIRA, C.H.A.F. Avaliação da consistência das argamassas industrializadas projetadas utilizando o método vane. Revista de Ciência e Tecnologia de Materiais de Construção Civil, v.2, n.1, p.54-63, 2005.

BAUER, E.; SOUSA, J.G.G.; GUIMARÃES, E.A. Estudo da tensão de escoamento de argamassas, no estado fresco, utilizando o equipamento vane tester de laboratório. In: Jornadas Sudamericanas de Ingeniería Estructural Mendoza, 31. Anais... Argentina, p.10, 2004.

BERTOL, I.; GOMES, K.E.; DENARDIN, R.B.N.; MACHADO, L.A.Z.; MARASCHIN, G.E. Propriedades físicas do solo relacionadas a diferentes níveis de oferta de forragem numa pastagem natural. Pesquisa Agropecuária Brasileira, Brasilia, v.33, n.2, p.779-786, 1998.

BRAIDA, J.A. Matéria orgânica e resíduos vegetais na superfície do solo e suas relações com o comportamento mecânico do solo sob plantio direto. 2004. 97f. Dissertação (Doutorado em Ciência do solo). Universidade Federal de Santa Maria, Santa Maria - RS, 2004.

BRAIDA, J.A.; REICHERT, J.M.; REINERT, D.J.; SEQUINATTO, L. Elasticidade do solo em função da umidade e do teor de carbono orgânico. Revista Brasileira de Ciência do Solo, Viçosa, MG, v.32, n.1, p.477-485, 2008.

BRAIDA, J.A.; REICHERT, J.M.; REINERT, D.J.;
SOARES, J.M.D. Coesão e atrito interno associados aos teores de carbono orgânico e de água de um solo franco arenoso. Ciência Rural, Santa Maria, v.37, n.6, p. 2007.

CAPUTO, H.P. Mecânica dos solos e suas aplicações. 5.ed. Rio de Janeiro: Livros técnicos e científicos, v.1, 1980, 219p.

CARDIM, R.D. Estudo da resistência de resíduos sólidos urbanos por meio de ensaios de cisalhamento direto de grandes dimensões. 2008. 107f. Dissertação (Mestrado em Geotecnia) Universidade de Brasília, Brasília, 2008.

CAVAlCANTE, E.H. Mecânica dos solos II. Aracaju-SP: Universidade Federal de Sergipe, Centro de ciências exatas e tecnologia, Departamento de engenharia civil, 2006. 75p. (Notas de aula).

CONTE, O.; LEVIEN, R.; TREIN, C.R.; CEPIK, C.T.C.; DEBIASI, H. Demanda de tração em haste sulcadora na integração lavoura pecuária com diferentes pressões de pastejo e sua relação com o estado de compactação do solo. Engenharia Agrícola, Jaboticabal, v.27, n.1, p.220-228, 2007.

DEXTER, A.R.; BIRD, N.R.A. Methods for predicting the optimum and the range of soil water contents for tillage based on the water retention curve. Soil and Tillage Research, Amsterdam, v.57, n.7, p.203-212, 2001.

EMPRESA BRASILEIRA DE PESQUISA AGROPECUÁRIA. Centro Nacional de Pesquisa de Solos. Manual de métodos de análise de solo. 2. ed. Rio de Janeiro: Ministério da Agricultura e Abastecimento, 1997. 212 p.

FURLAN, A.P. Estimativa da tensão de préadensamento de argilas saturadas através do ensaio de palheta: Extensão para limites de liquidez superiores a 70\%. 2000. 150f. Dissertação (Mestrado em Engenharia Civil). Universidade Estadual de Campinas, Campinas - SP, 2000.

IMHOFF, S.; SILVA, A.P.; TORMENA, C.A. 
Aplicação da curva de resistência no controle da qualidade física de um solo sob pastagem. Pesquisa Agropecuária Brasileira, Brasília, v.35, n.7, p.1493-1500, 2000.

KOAKOSKI, A.; SOUZA, C.M.A.; RAFULL, L.Z.L.; SOUZA, L.C.F.; REIS, E.F. Desempenho de semeadora-adubadora utilizando-se dois mecanismos rompedores e três pressões da roda compactadora. Pesq. agropec. bras., Brasília, v.42, n.5, p.725-731, 2007.

LONGO, R.M. Modificações em parâmetros físicos e químicos de Latossolo Argiloso decorrentes da substituição da floresta Amazônica e do Cerrado por pastagens. 1999. 135f. Dissertação (Doutorado em Engenharia Agrícola). FEAGRI/UNICAMP, Campinas- SP, 1999.

McCORMACK, D.E. \& WILDING, L.P. Soil properties influencing strength of Cranfield and Geeburg soils. Soil Science Society American Journal, New York, v.43, n.1, p.167-173, 1979.

MELLO, C.R. et al. Estimativa da capacidade de campo baseada no ponto de inflexão da curva característica. Ciência e Agrotecnologia, Lavras, v.26, n.4, p.836-841, 2002.

NGUYEN, N.Q.; BOGER, D.V. Direct yield stress measurement with the vane method. Journal of Rheology, v.29, n.3, p.335-347, 1985.

NUNES, A.H.B. Compressibilidade e resistência ao cisalhamento de um latossolo cultivado com eucalipto. 2010. 81f. Dissertação (Mestrado em Ciência do Solo). Universidade Federal de Lavras, MG, 2010.

OLIVEIRA, G.C.; DIAS JUNIOR, M.S.; RESCK, D.V.S.; CURI, N. Caracterização química e físicohídrica de um Latossolo Vermelho após vinte anos de Manejo e cultivo do solo. Revista Brasileira de Ciência do Solo, Viçosa, MG, v.28, n.2, p.327336, 2004.

PINTO, C.S. Curso básico de mecânica dos solos. São Paulo: Oficina de textos, 2000, p.247.
PROFFITT, A.P.B.; BENDOTTI, S.; HOWELL, M.R.; EASTHAM, J. The effect of sheep trampling and grazing on soil physical properties and pasture growth for a Red-Brown earth. Australian Journal of Agricultural Research, Melbourne, v.44, n.2, p.317-331, 1993.

SÁ, J.C.M. Reciclagem de nutrientes dos resíduos culturais, e estratégia de fertilização para a produção de grãos no sistema plantio direto. In: SEMINÁRIO SOBRE SITEMA PLANTIO DIRETO NA UFV, 1, 1998, Viçosa. Resumo das Palestras. Viçosa, Universidade Federal de Viçosa, 1998. p.19-61.

SCHNAID, F. Ensaios de campo e aplicação à engenharia de fundações. 1 ed. São Paulo, Oficina de textos, 2000. 189p.

SECCO, D.; REINERT, D.J.; REICHERT, J.M.; DA ROS, C.O. Produtividade e soja e propriedades físicas de um Latossolo submetido a sistemas de manejo e compactação. Revista Brasileira Ciência do Solo, Viçosa, MG, v.28, n.5, p.797-804, 2004.

SERAFIM, M.E.; VITORINO, A.C.T.; PEIXOTO, P.P.; SOUZA, C.M.A.; CARVALHO, D.F. Intervalo hídrico ótimo em um Latossolo Vermelho distroférrico sob diferentes sistemas de produção. Engenharia Agrícola, Jaboticabal, v.28, n.4, p.654-665, 2008.

SILVA, A.J.N.; CABEDA, M.S.V. Influência de diferentes sistemas de uso e manejo na coesão, resistência ao cisalhamento e óxidos de $\mathrm{Fe}, \mathrm{Si}, \mathrm{Al}$ em solo do tabuleiro costeiro de Alagoas. Revista Brasileira de Ciência do Solo, Viçosa, MG, v.29, n.3, p.447-457, 2005.

SILVA, A.J.N.; CARVALHO, F.G. Coesão e resistência ao cisalhamento relacionadas a atributos físicos e químicos de um Latossolo Amarelo de tabuleiro costeiro. Revista Brasileira de Ciência do Solo, Viçosa, MG, v.31, n.2, p.853-862, 2007.

SILVA, M.L.N.; CURI, N.; BLACANEAUX, P. Sistemas de manejo e qualidade de Latossolo Roxo. Pesquisa Agropecuária Brasileira, Brasília, v.35, 
n.12, p.2485-2492, 2000.

SILVA, R.B.; DIAS JUNIOR, M.S.; SANTOS, F.L.; FRANZ, C.A.B. Resistência ao cisalhamento de um Latossolo sob diferentes uso e manejo. Revista Brasileira de Ciência do Solo, Viçosa, MG, v.28, n.5, p.165-173, 2004.

SPERA, S.T.; SANTOS, H.P.; FONTANELI, R.S.; TOMM, G.O. Integração lavoura e pecuária e os atributos físicos de solo manejado sob sistema plantio direto. R. Bras. Ci. Solo, Viçosa, MG, v.33, n.1, p.129-136, 2009.

STRECK, C.A.; REINERT, D.J.; REICHERT, J.M.; KAISER, D.R. Modificações em propriedades físicas com a compactação do solo causada pelo tráfego induzido de um trator em plantio direto. Ciência Rural, Santa Maria, v.34, n.3, p.755-760, 2004.

TERZAGHI, K.; PECK, R. Mecânica dos solos na prática da engenharia. Rio de Janeiro: Ao livro técnico, 1962. 659p.

TRINDADE, T.P.; IASBIK, I.; LIMA, D.C.; MINETTE,E.; SILVA, C.H.C.; CARVALHO, C.A.B.; BUENO, B.S.; MACHADO, C.C.Estudos laboratoriais do comportamento de um solo residual arenoso reforçado com fibras de polipropileno, visando à aplicação em estradas florestais. Revista Árvore, Viçosa, MG, v. 30 n. 2, p.215-222, 2006.

VARGAS, M. Introdução a Mecânica dos solos. 1. ed. Brasil: McGraw-Hill do Brasil, 1977, 509p. 